\title{
Estrogen receptor expression in normal breast epithelium in invasive ductal carcinoma
}

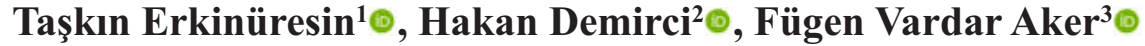

${ }^{1}$ Department of Pathology, University of Health Sciences, Bursa Yüksek İhtisas Training and Research Hospital, Bursa, Turkey ${ }^{2}$ Department of Family Medicine, University of Health Sciences, Bursa Yüksek Ihtisas Training and Research Hospital, Bursa, Turkey ${ }^{3}$ Department of Pathology, University of Health Sciences, Haydarpaşa Numune Training and Research Hospital, Bursa, Istanbul, Turkey

\section{ABSTRACT}

Objectives: Invasive ductal carcinomas (IDCs) are the most important group of malignant breast tumors and constitute $75-80 \%$ of breast carcinomas. While IDCs often present with ductal carcinoma in situ (DCIS), they sometimes include a low level of DCIS or they do not include any accompanying DCIS at all. We planned this study to compare estrogen receptor (ER) expression levels in normal mammary epithelium in IDCs with extensive DCIS (Group I) and IDCs without DCIS (Group II).

Methods: Eighty IDC cases selected from among samples that were analyzed in our pathology laboratory. The cases were assessed retrospectively in light of immunohistochemical analysis results and pathology reports. Evaluation of immunohistochemistry: ER positivity in IDC was defined with a nuclear staining of more than $10 \%$ of cancer cells regardless of intensity of staining. Presence of cells showing nuclear staining for normal breast epithelium was classified in 4 groups according to their quantity and intensity. These were: 0 -None: No staining was observed, 1-Single: One or two positive cells, 2-Dispersed: Dispersed positive cells surrounded by negative cells, 3-Adjoined: 10 or more positive cells contacting each other.

Results: Statistically no significant difference was found between Group I and Group II in terms of ER expression. Group I were more prevalent in younger and in the premenopausal period than Group II.

Conclusions: According to our study, there was no difference between Group I and Group II in terms of ER expression. But the significantly presence Group I in more young people and in premenopausal women suggests that these carcinomas develop due to high estrogen levels and that Group II develop independently than estrogen. This suggests that these groups may have different carcinogenesis and etiologies. We therefore think that this first study on IDCs with extensive DCIS and IDCs without DCIS should be supported by new research studies.

Keywords: Estrogen reseptor, breast epithelium, invasive ductal carcinoma, ductal carcinoma in situ

$\mathrm{B}$ reast cancer is the second most prevalent type of cancer throughout the world and it is the fifth most common cause of death-related to cancer [1]. Several researchers believe that breast carcinogenesis is a multi-step process [2], yet the etiologic mecha- nisms of breast carcinogenesis are not yet completely understood.

Histologically, estrogen receptor (ER) is expressed in approximately $4-15 \%$ of normal human mammary epithelial cells (HMEC) [3, 4]. ER has a key role in 
progression of early breast lesions towards breast cancer [5]. Moreover, ER is an admitted factor of prognosis and prediction for breast cancer [6]. More than $50 \%$ of malignant neoplasms coming from breast gland epithelium are ER+ [7]. It is also reported that estradiol causes breast cancer formation with its both ER dependent and genotoxic ER - free effects [8]. Another study suggests that breast cancers of gene expression patterns ER+ and ER- can originate from different stem cells and ER- breast cancers develop independently from estrogen $[9,10]$. All this information and additional research performed in the past fifty years show that estrogen and ERs have important roles in breast carcinogenesis [11, 12].

Invasive ductal carcinomas (IDCs) are the most important group of malignant breast tumors and constitute $75-80 \%$ of breast carcinomas $[13,14]$. While IDCs often present with ductal carcinoma in situ (DCIS), they sometimes include a low level of DCIS or they do not include any accompanying DCIS at all. If there exists a DCIS in or around the IDC that constitutes at least $25 \%$ of the neoplasm, this is called IDC including extensive DCIS. When invasive ductal carcinomas are accompanied by DCIS, there is a significant association between histological degrees of IDC and DCIS components [15]. This hypothesis is supported by genetic studies showing similar patterns of loss of heterozygosity ( $\mathrm{LOH})$ in both invasive and DCIS components of the same tumor [16]. ER expression in breast tissue is higher in the epithelium showing proliferative changes around the carcinoma [17]. A positive correlation of ER levels is also reported between tumor and benign tissue neighboring the tumor [18].

The rate of ER positive cells in premenopausal women is between $4 \%$ and $15 \%$ depending on the phase of menstrual cycles. These cells are dispersed one by one and they are surrounded by ER negative cells $[2,19,20]$. The number of ER positive cells increases with advanced age [21].

We planned this study to compare ER expression levels in normal mammary epithelium around carcinomas in women with IDC with extensive DCIS (a rate of $30 \%$ and above) (Group I) and without DCIS (a rate of 5\% and less) (Group II). Moreover, we analyzed the association between the two groups in terms of parameters such as age, menopausal status, tumor diameter, number of tumor foci, Nottingham histolog- ical grade, ER in carcinoma, progesterone receptor (PR) and C-erb-B2 expression status, lymph node metastasis status and also status of these parameters in all IDCs.

\section{METHODS}

Ethics committee approval for the study was obtained from the clinical research ethics committee of our institution. A total of 80 IDC cases selected from among breast mastectomy samples that were analyzed in our pathology laboratory were assessed. Forty-two of these were Group I and 38 were Group II. The cases were assessed retrospectively in light of immunohistochemical analysis results, pathology reports and information gathered from interrogations through telephone conversations.

The samples were paraffin-embedded blocks obtained from pathologic samples of 80 female patients (Group I 42 female patients and group II 38 female patients) who underwent mastectomy or breast protective surgical treatment in our hospital. In routine standard sampling, 3 samplings were performed on average from the tumor tissue.

The samples were fixed in $10 \%$ neutral buffered formalin for 24-48 hours and were embedded in paraffin. In each case, a sufficient tumor sample and a block including normal breast tissue around the tumor were selected. Dako EnVision+kit (DakoCytomation,

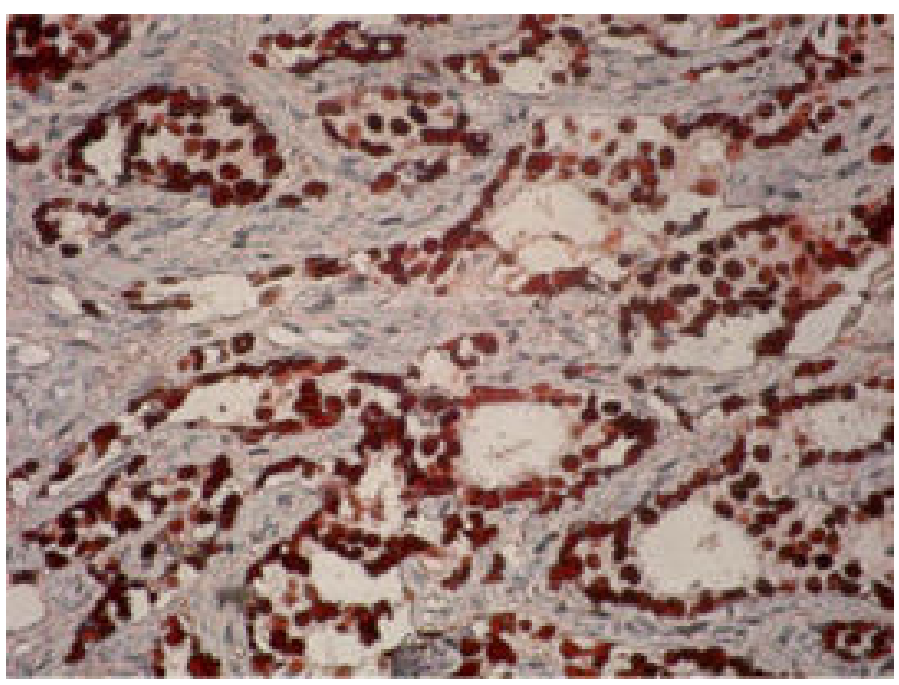

Fig. 1. Estrogen receptor positivity in invasive ductal carcinoma. 


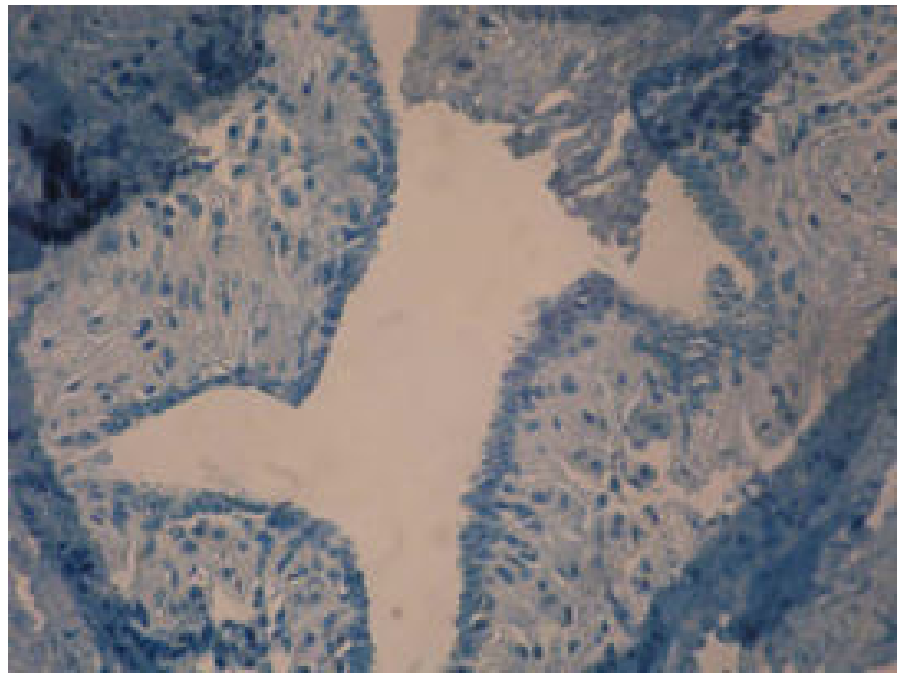

Fig. 2. Estrogen receptor expression pattern group 0: No staining is observed in normal breast ductus epithelium.

Glostrup, Denmark) was used manually following the manufacturer's instructions. Preparations were deparaffinized in xylene and rehydrated gradually in ethanol/water mixture series. Antigen retrieval process was applied to preparations, which were heated in a water bath of 95-99 $\mathrm{C}$ for 40 minutes in "target retrieval solution high $\mathrm{pH}$ (Dakocytomation)". After 20 minutes of cooling, sections were processed with primary antibody for 30 minutes following exposure to $3 \%$ hydrogen peroxide for 5 minutes at room temperature. Monoclonal mouse anti-human ER

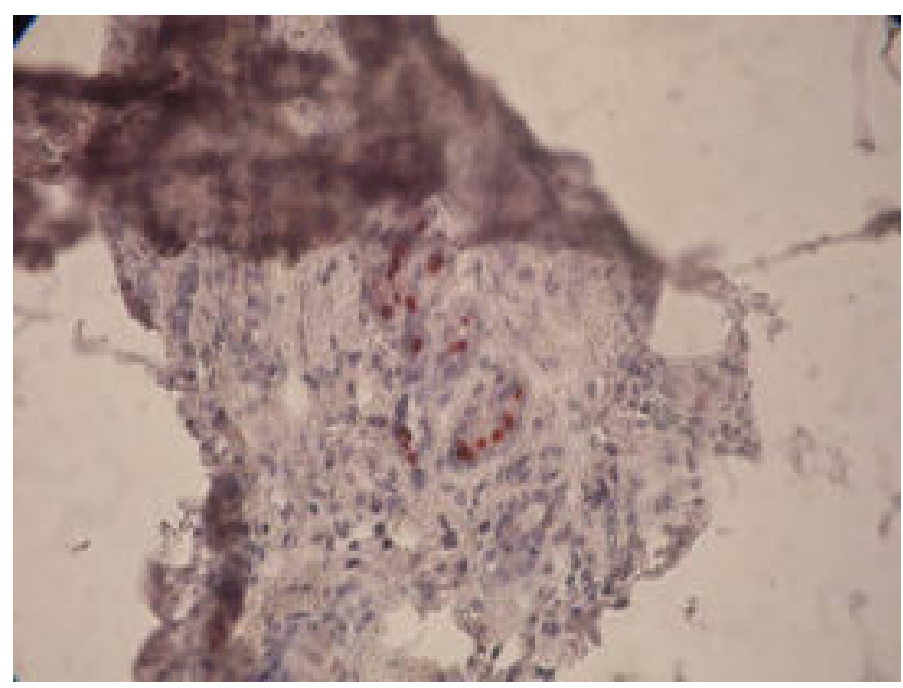

Fig. 4. Estrogen receptor expression pattern group 2: There is linear or dispersed cellular staining consisting of less than 10 cells adjoined to each other in normal breast ductus epithelium.

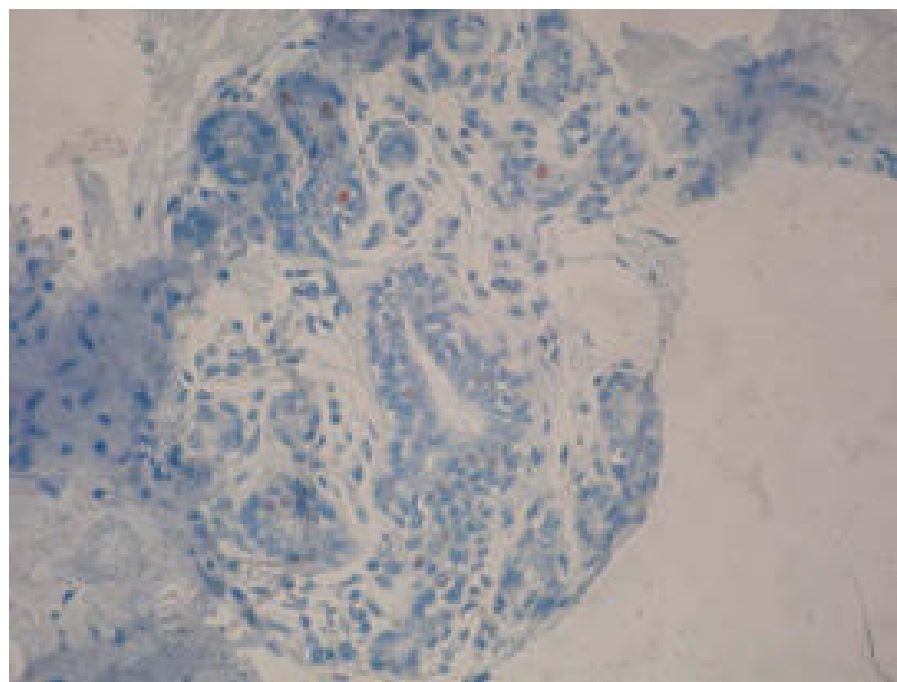

Fig. 3. Estrogen receptor expression pattern group 1: Ductus epithelium cells are observed with one or two stained cells in normal breast ductus epithelium.

(clone 1d5; Dakocytomation) antibody was used at $1 / 50$ dilution.

Evaluation of immunohistochemistry: ER positivity in IDC was defined with a nuclear staining of more than $10 \%$ of cancer cells regardless of intensity of staining (Fig. 1). Presence of cells showing nuclear staining for normal breast epithelium was classified in 4 groups according to their quantity and intensity. These were: 0-None: No staining was observed (Fig. 2), 1-Single: One or two positive cells (Fig. 3), 2-Dispersed: Dispersed positive cells surrounded by negative cells (Fig. 4), 3-Adjoined: 10 or more positive cells contacting each other (Fig. 5) [22].

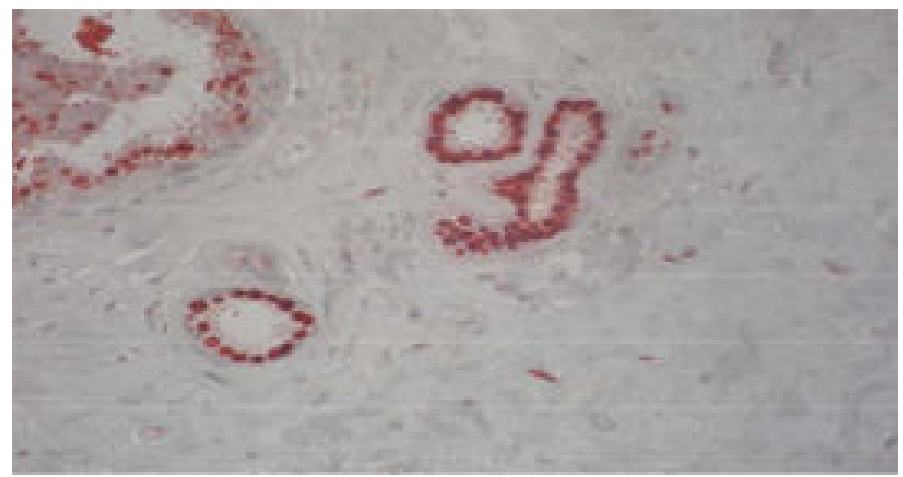

Fig. 4. Estrogen receptor expression pattern group 3: There is adjoining linear staining consisting of more than 10 cells in normal breast ductus epithelium. 
Table 1. Relation between negative and positive distribution of ER expression pattern groups $0,1,2,3$ in normal breast epithelium around the carcinoma

\begin{tabular}{llccccc}
\hline & & ER Pt. & ER Pt. & ER Pt. & ER Pt. & $p$ value \\
& & NME 0 & NME 1 & NME 2 & NME 3 & \\
\hline \multirow{2}{*}{ ER in IDC } & Negative & $8(100.0 \%)$ & $5(29.4 \%)$ & $10(30.3 \%)$ & $6(31.6 \%)$ & $\chi^{2}: 14.7$ \\
& Positive & $0(0.0 \%)$ & $12(70.6 \%)$ & $23(69.7 \%)$ & $13(68.4 \%)$ & $\mathbf{0 . 0 0 2}$ \\
\hline
\end{tabular}

$\mathrm{ER}=$ Estrogen receptor, $\mathrm{Pt}=$ pattern, $\mathrm{NME}=$ normal mammary epithelium, $\mathrm{IDC}=$ invasive ductal carcinoma

\section{Statistical Analysis}

In this study, statistical analyses were performed with NCSS 2007 package software. Besides descriptive statistical methods (mean, standard deviation) for assessment of data, Kruskal Wallis (KW) test was used for multiplex group comparisons, Dunn's multiple comparison test was used for subgroup comparisons, Mann-Whitney (MW) U test was used for comparison of double groups and Chi-square test was used for comparison of qualitative data. The results were assessed at a level of significance of $p<$ 0.05 .

\section{RESULTS}

Statistically no significant difference was found between Group I and Group II in terms of ER expression in normal breast epithelium around the carcinoma. Statistically no significant difference was found between Group I and Group II in terms of expression pattern in normal breast epithelium around the carcinoma $(0,1,2$ and 3$)$, tumor diameter, metastatic lymph node quantity, metastatic lymph node involvement phase, total Nottingham Histological Score and Nottingham histological grade.

In invasive ductal carcinomas, statistically a significant difference was observed between expression pattern groups $(0,1,2$ and 3$)$ of ER in normal breast epithelium around the carcinoma and expression of ER in the carcinoma $(p=0.002)$ (Table $1)$. There was a parallelism between ER expression in normal breast epithelium around IDC and ER expression in IDC.

There were 42 cases in Group I and 38 cases in Group II. Ages of these cases were between 27 and 84 (mean age: 55.88 years). Mean age in Group I was $52.45 \pm 13.31$ years, and mean age in Group II was $59.68 \pm 14.83$ years, and statistically there was a significant difference between the mean ages of the groups $(\mathrm{MW}=564, \mathrm{p}=0.025)$. Group I cases were more prevalent in younger ages than group II cases.

A significant difference was observed between distribution of menopause status of cases of the two groups $(p=0.002)$ (Table 2). While group I were more prevalent in the premenopausal period, group II were more prevalent in the postmenopausal period. Approximately $54.8 \%$ of group I were in the premenopausal period and this rate was $21.1 \%$ of group II.

In invasive ductal carcinomas, postmenopausal presence was significantly lower in the ER expression pattern group 0 compared to ER expression pattern groups 1,2 and 3 ( $p=0.018$ ) (Table 3 ). While the number of cases showing ER expression in normal breast epithelium around IDC were much more for postmenopausal, cases without ER expression were usually premenopausal cases.

Statistically, a significant difference was found between distribution of ER expression pattern groups in normal breast epithelium around the carcinoma in invasive ductal carcinomas and the arithmetic mean of metastatic lymph node quantity $(p=0.041)$.

Table 2. Distribution of premenopausal / postmenopausal status of Group I and II cases

\begin{tabular}{lccc}
\hline $\begin{array}{l}\text { Menopause } \\
\text { Status }\end{array}$ & $\begin{array}{c}\text { Group I } \\
\text { n (\%) }\end{array}$ & $\begin{array}{c}\text { Group II } \\
\text { n (\%) }\end{array}$ & $p$ value \\
\hline Premenopausal & $23(54.8 \%)$ & $8(21.1 \%)$ & $\boldsymbol{\chi}^{\mathbf{2}: 9.55}$ \\
Postmenopausal & $19(45.2 \%)$ & $30(78.9 \%)$ & $\mathbf{0 . 0 0 2}$ \\
\hline
\end{tabular}


Table 3. The relationship between the expression pattern groups $0,1,2$ and 3 of $E R$ in normal breast epithelium around the carcinoma and the menopausal status

\begin{tabular}{lccccc}
\hline Menopause Status & ER Pt. & ER Pt. & ER Pt. & ER Pt. & $p$ value \\
& NME 0 & NME 1 & NME 2 & NME 3 & \\
\hline Premenopausal & $7(87.5 \%)$ & $4(23.5 \%)$ & $14(38.9 \%)$ & $6(31.6 \%)$ & $\chi^{\mathbf{2}: 10}$ \\
Postmenopausal & $1(12.5 \%)$ & $13(76.5 \%)$ & $22(61.1 \%)$ & $13(68.4 \%)$ & $\mathbf{0 . 0 1 8}$ \\
\hline
\end{tabular}

$\mathrm{ER}=$ Estrogen receptor, $\mathrm{Pt}=$ pattern, $\mathrm{NME}=$ normal mammary epithelium

Table 4. Relation between distribution of ER expression pattern in normal breast epithelium around the carcinoma and the arithmetic mean of metastatic lymph node quantity

\begin{tabular}{|c|c|c|c|c|c|c|}
\hline & $\begin{array}{l}\text { ER Pt. } \\
\text { NME 0 }\end{array}$ & $\begin{array}{l}\text { ER Pt. } \\
\text { NME } 1\end{array}$ & $\begin{array}{l}\text { ER Pt. } \\
\text { NME } 2\end{array}$ & $\begin{array}{l}\text { ER Pt. } \\
\text { NME } 3\end{array}$ & KW & $p$ value \\
\hline $\begin{array}{l}\text { Metastatic lymph node } \\
\text { quantity }\end{array}$ & $6 \pm 0.01$ & $\begin{array}{l}11.14 \pm \\
9.53\end{array}$ & $4.19 \pm 3.1$ & $\begin{array}{c}4.36 \pm \\
4.74\end{array}$ & 6.48 & 0.041 \\
\hline
\end{tabular}

$\mathrm{ER}=$ Estrogen receptor, $\mathrm{Pt}=$ pattern, $\mathrm{NME}=$ normal mammary epithelium, $\mathrm{KW}=$ Kruskal-Wallis test

However, when Dunn's multiple comparison test was applied, metastatic lymph node quantity of group 1 of ER expression pattern in normal breast epithelium around the carcinoma (slightly positive) was significantly higher than the number of metastatic lymph nodes of pattern groups 2 and 3 (medium and highly positive) $(p=0.034, p=0.046)$. Statistically, no significant difference was observed between the other pattern groups $(p>0.05)$ (Table 4 and 5). Much

\section{Table 5. Relation between distribution of ER expression pattern in normal breast epithelium around the carcinoma and the arithmetic mean of metastatic lymph node quantity}

\begin{tabular}{lc}
\hline $\begin{array}{l}\text { Dunn's Multiple Comparison } \\
\text { Test }\end{array}$ & $\begin{array}{c}\text { Metastatic Lymph } \\
\text { Node Quantity }\end{array}$ \\
\hline ER Pt. NME 0 / ER Pt. NME 1 & 0.631 \\
ER Pt. NME 0 / ER Pt. NME 2 & 0.969 \\
ER Pt. NME 0 / ER Pt. NME 3 & 0.978 \\
ER Pt. NME 1 / ER Pt. NME 2 & $\mathbf{0 . 0 3 4}$ \\
ER Pt. NME 1 / ER Pt. NME 3 & $\mathbf{0 . 0 4 6}$ \\
ER Pt. NME 2 / ER Pt. NME 3 & 0.998 \\
\hline ER = Estrogen receptor, Pt = pattern, NME = normal \\
mammary epithelium
\end{tabular}

more lymph node metastasis occurs in cases with a slightly lower level of ER expression (Pattern group 1) in normal breast epithelium around IDC compared to the cases with medium and high levels of ER expression (Pattern groups 2 and 3).

In invasive ductal carcinomas, statistically no significant difference was observed between the ER expression pattern groups $(0,1,2$ and 3$)$ in normal breast epithelium around the carcinoma and tumor diameter, age, Nottingham histological grade total score, Nottingham histological grade, metastatic lymph node involvement phase, PR in carcinoma, Cerb-B2 expression and focality.

\section{DISCUSSION}

In our study, the ER expression level in surrounding breast ductus epithelium did not show a difference between the group I and group II. We could not find any significant difference between these two groups in terms of other variables (such as lymph node metastasis, tumor diameter, multifocality, histological score, PR in IDC and C-erb-B2 positivity). Similar to our study, Ahmed et al. [19] did not detect a significant difference in their study of 100 consecutive cases between groups with and without extensive DCIS in 
terms of tumor size, histological grade, nodal status, pathologic phase, ER and PR expression. Also in the study of Stuart et al. [23], no direct correlation was detected in case groups with extensive DCIS fields with multifocality or other parameters. On the other hand, Fisher et al. [24] showed that the most significant difference was the increase of multicentricity in cases with extensive DCIS.

According to our study, the relation between ER expression pattern (pattern groups $0,1,2$ and 3 ) in normal ductus epithelium around the carcinoma in IDCs and negativity and positivity of ER in the carcinoma was statistically significant. In expression pattern group 0 , positivity of ER in the carcinoma was not observed. Moreover, ER positivity in the carcinoma was observed at a rate of $69.5 \%$ on average in ER expression pattern groups 1, 2 and 3 in normal breast epithelium around the carcinoma. Positivity of ER in normal breast epithelium around the carcinoma in IDCs was detected in $90 \%$ of the cases ( 72 of 80 cases). Like our study, Umekita et al. [22], who compared ER expression in surrounding breast tissue and ER expression in the tumor, found this rate to be $99 \%$ (217 of 220 cases). In contrast to our study, Yang et al. [25] found ER expression levels in the terminal ductal lobular unit in ER positive tumors to be significantly low. Whereas in our study, ER negativity was not detected at all in normal breast epithelium in positive IDCs, and low ER positivity was at a rate of $25 \%$, medium level ER positivity was $48 \%$ and high level of ER positivity was $27 \%$ (Table 1).

Statistically, no significant difference was observed between ER expression pattern groups distribution in normal breast epithelium around invasive ductal carcinomas and the arithmetic mean of ages of the cases. In addition, it is remarkable that the mean age of the cases increased as the ER expression increased in surrounding normal breast epithelium. In particular, while the mean age of cases without ER expression or cases with low level of expression was 45, the mean age of cases with high level of ER expression was 60. Kumar et al. [26] measured ER expression levels in tumor and normal breast epithelium surrounding the tumor with enzyme immunoassay and compared them with age. In parallel with our findings, while tumor ER levels increased with age, no change was seen in ER levels in normal breast epithelium around the tumor in different age groups. Barnes et al. [27] observed in their study that the rate of ER positive cells slightly increased with age in ordinary ductal hyperplasia. In addition to this, in all atypical ductal hyperplasia (ADH), lobular carcinoma in situ and DCIS cases, a high level of ER positivity (Pattern group 3) was observed in most of the lesions. However, this relation between ER positive cell quantity and age was lost with these lesions. This situation, in one sense, shows the autonomy of proliferation of ER expression or cells expressing receptor. This hypothesis is based on deterioration of configuration of ER positive cell quantity or receptor expression in the $\mathrm{ADH}$ phase, which starts abnormal expression of cyclins and other cell cycle proteins. These results suggest a hypothesis that can explain the lack of a significant relation between age and expression patterns of ER in normal breast ductus epithelium around IDC in our study. Woolcott et al. [28], in parallel with our findings, used breast excisional biopsies taken for diagnostic purposes as a control group in their research. While there was a significant relation between age and ER levels in nonneoplastic tissue in groups of breast cancer cases and the control group, they could not detect a relation between age and ER levels in case groups. In another study, Giani et al. [29], in parallel with our findings, determined that the mean age of ER positive women was higher than ER negative women. Throughout society, besides a significant positive relation between ER positivity and age, there is a tendency towards ER positivity in postmenopausal women rather than premenopausal women. The results of Rochman et al. [30] and Ellinidi et al. [31] are in parallel with each other and show great similarity with our findings. They indicate that in primary breast cancers, there is a positive relation between age of the patients and increasing incidence of ER positive tumors.

In our study, statistically no significant difference was observed between the two groups in terms of positive and negative distribution of ER in carcinomas. Likewise, in the study of Xuefeng et al. [32], no difference was detected between these two groups. The positive correlation in this case is the relation between DCIS and the invasive component accompanying DCIS, and both in situ and invasive components have the same positive and negative rate. The only important difference is that staining density 
and extent of ER in the in situ component is much more than in the invasive component.

\section{CONCLUSION}

We performed the first study to investigate ER expression between group I and group II. According to our study, there was no difference between group I and group II in terms of ER expression in carcinoma and in normal breast ductus epithelium around the carcinoma. But there was a significant difference between group I and group II in terms of mean age and menopause status of cases. The significantly presence of group I cases in more young people and in premenopausal women suggests that these carcinomas develop due to high estrogen levels and that group II cases develop independently than estrogen. This suggests that these groups may have different carcinogenesis and etiologies. We therefore think that this first study on group I cases and group II cases should be supported by new research studies.

\section{Conflict of interest}

The authors disclosed no conflict of interest during the preparation or publication of this manuscript.

\section{Financing}

The authors disclosed that they did not receive any grant during conduction or writing of this study.

\section{REFERENCES}

1. http://www.who.int/news-room/fact-sheets/detail/cancer. Access date: 06.10.2018.

2. Wu T, Li Y, Gong L, Lu JG, Du XL, Zhang WD, et al. Multistep process of human breast carcinogenesis: a role for BRCA1, BECN1, CCND1, PTEN and UVRAG. Mol Med Rep 2012;5:305-12.

3. Clarke RB, Howell A, Potten CS, Anderson E. Dissociation between steroid receptor expression and cell proliferation in the human breast. Cancer Res 1997;57:4987-91.

4. Oh H, Eliassen AH, Wang M, Smith-Warner SA, Beck AH, Schnitt SJ, et al. Expression of estrogen receptor, progesterone receptor, and Ki67 in normal breast tissue in relation to subsequent risk of breast cancer. NPJ Breast Cancer 2016;2:16032.

5. Petersen OW, Hoyer PE, van Deurs B. Frequency and distribution of estrogen receptor-positive cells in normal, nonlactating human breast tissue. Cancer Res 1987;47:5748-51. 6. Henderson IC, Patek AJ. The relationship between prognostic and predictive factors in the management of breast cancer. Breast Cancer Res Treat 1998;52:261-88.

7. Osborne CK, Yochmowitz MG, Knight WA, 3rd, McGuire WL. The value of estrogen and progesterone receptors in the treatment of breast cancer. Cancer 1980;46(12 Suppl):2884-8.

8. Santen R, Cavalieri E, Rogan E, Russo J, Guttenplan J, Ingle $\mathrm{J}$, et al. Estrogen mediation of breast tumor formation involves estrogen receptor-dependent, as well as independent, genotoxic effects. Ann N Y Acad Sci 2009;1155:132-40.

9. Perou CM, Sorlie T, Eisen MB, Van de Rijn M, Jeffrey SS, Rees CA, et al. Molecular portraits of human breast tumours. Nature 2000;406:747-52.

10. Sorlie T, Perou CM, Tibshirani R, Aas T, Geisler S, Johnsen $\mathrm{H}$, et al. Gene expression patterns of breast carcinomas distinguish tumor subclasses with clinical implications. Proc Natl Acad Sci USA 2001;98:10869-74.

11. Robertson JF. Oestrogen receptor: a stable phenotype in breast cancer. Br J Cancer 1996;73:5-12.

12. Wooster R, Weber BL. Breast and ovarian cancer. N Engl J Med 2003;348:2339-47.

13. Rosen PP. The pathological classification of human mammary carcinoma: past, present and future. Ann Clin Lab Sci 1979;9:144-56.

14. Tulinius H, Bjarnason O, Sigvaldason H, Bjarnadottir G, Olafsdottir G. Tumours in Iceland, 10. Malignant tumours of the female breast. A histological classification, laterality, survival and epidemiological considerations. APMIS 1988;96:229-38.

15. Gupta SK, Douglas-Jones AG, Fenn N, Morgan JM, Mansel RE. The clinical behavior of breast carcinoma is probably determined at the preinvasive stage (ductal carcinoma in situ). Cancer 1997;80:1740-5.

16. Rosen PP. Invasive duct carcinoma: assesment of prognosis, morphologic prognostic markers, and tumor growth rate. Chapter 12. In: Rosen's Breast Pathology. Philadelphia, PA: Lippincott, Williams \& Wilkins, 2008: pp.358-404.

17. Hurd TC, Sneige N, Allen PK, Strom EA, McNeese MD, Babiera GV, et al. Impact of extensive intraductal component on recurrence and survival in patients with stage I or II breast cancer treated with breast conservation therapy. Ann Surg Oncol 1997;4:119-24.

18. Rosen PP. Anatomy and physiological morphology. Chapter 1. In: Rosen's Breast Pathology. Philadelphia, PA: Lippincott, Williams \& Wilkins, 2008: pp.1-25.

19. Ahmed S, Tartter PI, Brower ST, Weiss SE, Brusco C, Bossolt $\mathrm{K}$, et al. Comparison of invasive cancers with and without extensive intraductal component. Breast Dis 1996;8:1-6.

20. Ricketts D, Turnbull L, Ryal G, Bakhshi R, Rawson NSB, Gazet J-C, et al. Estrogen and progesterone receptors in the normal female breast. Cancer Res 1991;51:1817-22.

21. Drife JO. Breast development in puberty. Ann N Y Acad Sci 1986;464:58-65.

22. Umekita Y, Souda M, Ohi Y, Rai Y, Sagara Y, Yoshida H. Expression of estrogen receptor alpha and progesterone receptor in normal human breast epithelium. In Vivo 2007;21:535-9.

23. Schnitt SJ, Connolly JL, Harris JR, Hellman S, Cohen RB. 
Pathologic predictors of early local recurrence in stage I and II breast cancer treated by primary radiation therapy. Cancer 1984;53:1049-57.

24. Fisher ER, Gregorio R, Redmond C, Vellios F, Sommers SC, Fisher B. Pathologic findings from the national surgical adjuvant breast project. (protocol no. 4): 1. Observations concerning the multicentricity of mammary cancer. Cancer 1975;35:247-54.

25. Xiaohong R. Yang, Jonine D. Figueroa, Stephen M. Hewitt, Roni T. Falk, Ruth M. Pfeiffer, Jolanta Lissowska, Beata Peplonska, Louise A. Brinton, Montserrat Garcia-Closas, and Mark E. Sherman. Estrogen receptor and progesterone receptor expression in normal terminal duct lobular units surrounding invasive breast cancer. Breast Cancer Res Treat 2013;137:83747.

26. Kumar VL, Srivastava A, Singhal R, Kumar V. Immunoreactive estrogen receptor in breast tumor and adjacent tissue: association with clinicopathological characteristics in Indian population. J Surg Oncol2005;89:251-5.

27. Barnes R, Masood S. Potential value of hormone receptor assay in carcinoma in situ of breast. Am J Clin Pathol
1990;94:533-7.

28. Woolcott CG, Sen Gupta SK, Hanna WM, Aronson KJ. Estrogen and progesterone receptor levels in nonneoplastic breast epithelium of breast cancer cases versus benign breast biopsy controls. BMC Cancer 2008;8:130.

29. Giani C, D’Amore E, Delarue JC, Mouriesse H, May-Levin F, Sancho-Garnier H, et al. Estrogen and progesterone receptors in benign breast tumors and lesions: Relationship with histological and cytological features. Int J Cancer 1986;37:7-10. 30. Rochman H, Conniff ES, Kuk-Nagle KT. Age and incidence of estrogen receptor positive breast tumors. Ann Clin Lab Sci 1985;15:106-8.

31. Ellinidi VN, Anikseeva NV, Goncharova OA, Krasnozhon DA, Fedorov KA. [Immunohistochemical investigation of estrogen and progesterone receptors in breast tumors]. Vopr Onkol 2004;50:234-6. [Article in Russian)

32. Jing X, Kakudo K, Murakami M, Nakamura Y, Nakamura M, Yokoi T, et al. Extensive intraductal component (EIC) and estrogen receptor (ER) status in breast cancer. Pathol Int 1998;48:440-7. 